\title{
Analysis of TbpA and TbpB functionality in defective mutants of Neisseria meningitidis
}

\author{
M. PINTOR, J. A. GÓMEZ, L. FERRÓN, C. M. FERREIRÓS and M. T. CRIADO \\ Departamento de Microbiología y Parasitologia, Facultad de Farmacia, Universidad de Santiago de \\ Compostela, Spain
}

\begin{abstract}
Iron uptake analysis suggested that the Neisseria meningitidis transferrin (Tf) binding proteins, TbpA and TbpB, form only one type of receptor complex. Mutants defective in the synthesis of either TbpA or TbpB, but not defective in both proteins, can bind Tf, suggesting that both proteins are surface exposed and function in Tf binding. Also, iron uptake from Tf into the meningococci did not require the presence of both Tbps. The TbpB-defective mutant incorporated $c .37 \%$ of the iron taken up by the wild-type strain, but this was insufficient for bacterial growth. The TbpA-defective mutant incorporated c. $50 \%$ of the iron taken up by the wild-type strain and was able to grow with $T f$ as the only iron source. Mouse antibodies specific for $\operatorname{TbpA}$ were able to block c. $70 \%$ of the iron uptake from $\mathrm{Tf}$ in the wild-type strain, whereas they blocked only $22 \%$ of iron uptake in the TbpB-defective mutant and did not block uptake in the TbpA-defective strain. These results emphasise that TbpA should be considered in future vaccine trials in which iron-restricted proteins are to be included in the vaccine formulation.
\end{abstract}

\section{Introduction}

The poor efficacy of polysaccharide anti-meningococcal vaccines has stimulated a search for alternative protective antigens. Some outer-membrane proteins (OMPs) are antigenic both in vivo and in vitro and show inter-strain cross-reactivity, the transferrin (Tf) binding proteins (Tbps: TbpA and $\mathrm{TbpB}$ ) being some of the most relevant $[1,2]$. These particular proteins are of interest because anti-TbpB antibodies are bactericidal and protective and can block iron uptake from $\mathrm{Tf}$, thus interfering with meningococcal growth [3]. The Tf-receptor complex (and its component proteins, TbpA and $\mathrm{TbpB}$ ) has been identified and purified [4], and studies on its structural, biochemical, functional and antigenic characteristics have been done $[1,2,4-6]$. However, some uncertainties such as the TbpA:TbpB ratio, the necessity of both proteins for iron uptake, their antigenic heterogeneity and the efficacy of specific antibodies still persist. In gonococci, TbpA-defective mutants are incapable of Tf-iron internalisation and growth [6], but mutants lacking $\mathrm{TbpB}$ can grow, although their iron-uptake efficiency is lowered [7]. In contrast, data obtained with meningo-

Received 1 July 1997; revised version accepted 23 Dec. 1997.

Corresponding author: Professor M. T. Criado. cocci suggest that both types of mutants are unable to grow with $\mathrm{Tf}$ as the only iron source and both proteins seem to be necessary in this species [8]. This study tried to define more precisely the role of each Tbp in Tf binding and iron uptake in $N$. meningitidis.

\section{Materials and methods}

N. meningitidis mutants obtained and described by Irwin et al. [8] were kindly provided by Professor P. Borriello (Department of Microbiology, Queen's Medical Centre, Nottingham). The wild-type strain was $N$. meningitidis $\mathrm{B} 16 \mathrm{~B} 6$ and mutants were $\mathrm{N} 16 \mathrm{~T} 2 \mathrm{~K}$ $\left(\mathrm{TbpA}^{+} \mathrm{TbpB}^{-}\right), \mathrm{N} 16 \mathrm{~T} 1 \mathrm{E}\left(\mathrm{TbpA}^{-} \mathrm{TbpB}^{+}\right)$and N16T 12EK $\left(\mathrm{TbpA}^{-} \mathrm{TbpB}^{-}\right)$. The strains were maintained at $-80^{\circ} \mathrm{C}$ and cultured in Mueller-Hinton medium $(\mathrm{MH}$; iron sufficient), MH-EDDA (MH with $39 \mu \mathrm{M}$ ethylene diaminodihydroxyacetic acid; iron restricted), or in an iron-restricted defined medium (mMBDM; used for uptake experiments) as described previously [9]. Binding of human transferrin was determined by a modified ELISA [10]. Kinetic assays and determinations of affinity and receptor copy numbers were done with ${ }^{125} \mathrm{I}-\left(\mathrm{Fe}_{2}\right) \mathrm{Tf}$ and $\mathrm{KCN}$-killed bacterial suspensions $[3,10]$. Uptake of ${ }^{55} \mathrm{Fe}$ was measured in live bacterial suspensions by ${ }^{55} \mathrm{Fe}_{2}$ - Tf (25\% saturation) [5] or ${ }^{55} \mathrm{Fe}$ complexes with organic acids [9]. The ability of mouse 
anti-TbpA serum (obtained by adsorption of antiTbpAB serum [3] with N16T1E cells) to block iron uptake from $\mathrm{Tf}$ was also determined in kinetic assays. Growth with human $\mathrm{Tf}$ as the only iron source was monitored in mMBDM medium containing $30 \mu \mathrm{M} \mathrm{Fe}_{2}-$ Tf [11].

\section{Results and discussion}

The characteristics of the binding of $\mathrm{Tf}$ by all strains are shown in Fig. 1. The kinetics are compatible with the presence of specific receptors, except for the double mutant. The wild-type strain bound almost twice as much $\left[{ }^{125} \mathrm{I}\right]-\mathrm{Tf}$ as the TbpA or TbpB mutants, which bound similar amounts of $\operatorname{Tf}$ (c. 1.6 pmoles $/ 10^{9}$ bacteria). The double mutant showed a very low binding, considered to be non-specific, and was not included in subsequent binding experiments. Binding data were analysed to estimate the number of receptor copies and their affinity constants $\left(\mathrm{K}_{\mathrm{a}}\right)$. Scatchard plots were linear and adjusted to a model of a single, simple and homogeneous population (Hill's coefficients close to 1.0$)$ with high correlation coefficients $(C \geqslant 0.95)$, both in the wild-type and in the isogenic mutants. Table 1 summarises the data on bound $\mathrm{Tf}$, Tf receptor

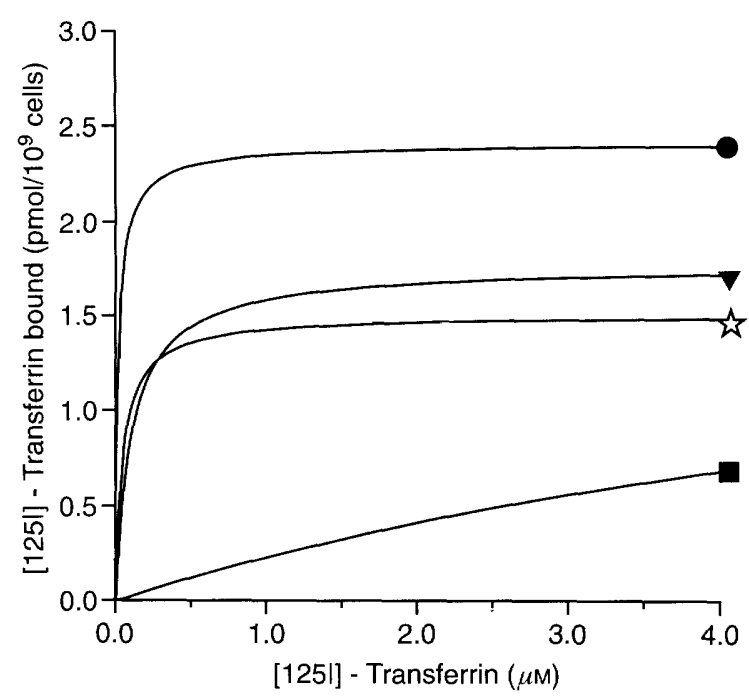

Fig. 1. Saturation kinetics of the binding of human transferrin to killed $N$. meningitidis strain B16B6 (wild-type, ) and its isogenic Tbp-defective mutants $\left(\mathrm{TbpA}^{-} / \mathrm{TbpB}^{+}, \mathbf{\nabla} ; \mathrm{TbpA}^{+} / \mathrm{TbpB}^{-}, \mathbf{\square} ; \mathrm{TbpA}^{-} / \mathrm{TbpB}^{-}\right.$, is) in a radiolabelled receptor assay with $\left[{ }^{125} \mathrm{I}\right]$-transferrin. numbers/cell and the corresponding affinity constants $\left(\mathrm{K}_{\mathrm{a}}\right)$ of the strains. The uptake kinetics of ${ }^{55} \mathrm{Fe}$ from $\mathrm{Tf}$ into the strains showed saturation at 15-20 min (data not shown). After $120 \mathrm{~min}$, the double mutant had not incorporated iron, and the $\mathrm{TbpB}$ and $\mathrm{TbpA}$ mutants had incorporated, respectively, $37 \%$ and $50 \%$ of the iron taken up by the wild-type strain. Iron uptake from low mol.wt ferric chelates (citrate, isocitrate, pyruvate, lactate and EDDA) was not affected by the mutations (data not shown). The effect of mouse anti-TbpA antibodies on the uptake of iron is also shown in Table 1. Only the blocking effect in the wild-type strain $(70 \%)$ was statistically significant (Mann-Whitney test; $\mathrm{p}<0.05$ ). Results of the growth assays done to study the effect of the mutations on the ability of $N$. meningitidis strains to use human $\mathrm{Tf}$ as the only source of iron are shown in Fig. 2. The TbpB and the double knock-out mutants showed almost negligible growth, but the TbpA mutant grew up to an optical density only slightly lower than that of the wild-type strain. All strains were unable to grow in the medium lacking an external iron source.

The quantification of the binding of human Tf and the determination of the number and affinity of the receptors for this molecule in each mutant allowed the differentiation of the affinity of the TbpA and

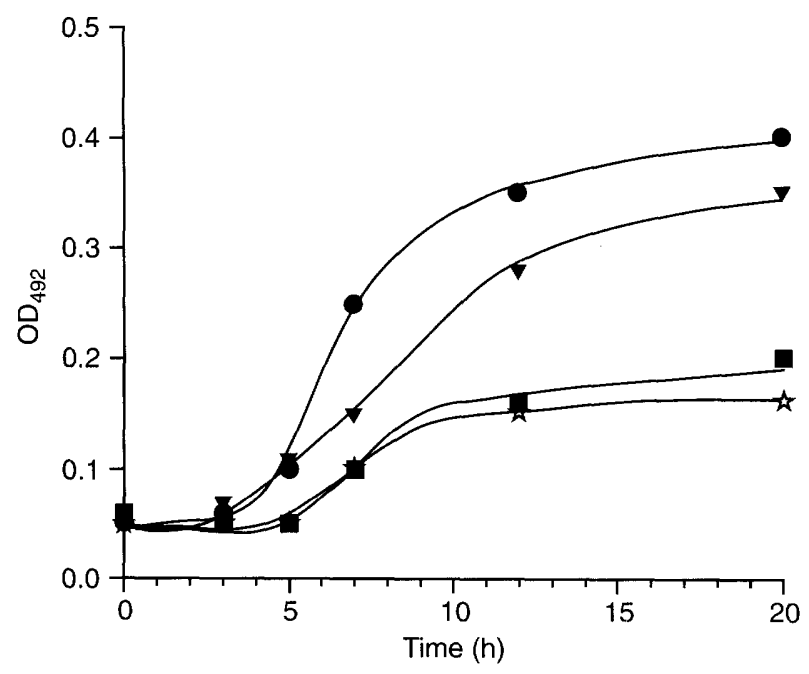

Fig. 2. Growth kinetics of N. meningitidis strain B16B6 (wild-type, and its isogenic Tbp-defective mutant strains $\left(\mathrm{TbpA}^{-} / \mathrm{TbpB}^{+}, \mathbf{\nabla} ; \mathrm{TbpA}^{+} / \mathrm{TbpB}^{-}, \mathbf{\square} ; \mathrm{TbpA}^{-} /\right.$ $\mathrm{TbpB}^{-}$, 3 ) in defined medium with iron-loaded human transferrin as the only iron source.

Table 1. Characteristics of the transferrin receptor system in $N$. meningitidis strain B16B6 (wild-type) and its isogenic TbpA and TbpB defective mutants

\begin{tabular}{llccrrr}
\hline Strain no. & Phenotype & $\begin{array}{c}\text { Bound transferrin } \\
\left(\mathrm{pmol} / 10^{9} \text { bacteria }\right)\end{array}$ & $\begin{array}{c}\mathrm{K}_{\mathrm{a}} \\
(\mathrm{L} / \mathrm{mol})\end{array}$ & $\begin{array}{c}\text { Receptors/ } \\
\text { cell }\end{array}$ & $\begin{array}{c}\text { Iron uptake* } \\
(\%)\end{array}$ & $\begin{array}{c}\text { Blocking of } \\
\text { uptake } \\
(\%)\end{array}$ \\
\hline B16B6 & $\mathrm{TbpA}^{+} \mathrm{TbpB}^{+}$ & 3.56 & $4.30 \times 10^{7}$ & $1044 \pm 160$ & 100 \\
N16T2K & $\mathrm{TbpA}^{+} \mathrm{TbpB}^{-}$ & 1.91 & $2.61 \times 10^{8}$ & $602 \pm 45$ & 70 \\
N16T1E & $\mathrm{TbpA}^{-} \mathrm{TbpB}^{+}$ & 1.95 & $1.62 \times 10^{7}$ & $814 \pm 42$ & 37 & 50 \\
\hline
\end{tabular}

*Expressed as a percentage of that of the wild-type strain.

${ }^{\dagger}$ Expressed as the percentage inhibition of uptake by anti-TbpA serum relative to the uptake in the same strain in the presence of non-immune serum. 
TbpB molecules for human Tf. The analyses show single and homogeneous receptor populations in all strains, in disagreement with the results of Cornelissen et al. [6] that suggested the existence of two different receptor populations in wild-type strains. The results of the present study also conflict with recent data by Powell et al. [12] which suggested that the two Tbps do not form a single $\mathrm{Tf}$ receptor. If either of these hypotheses were correct, the different affinities of the two receptor types (or the two Tbps) should have resulted in the detection of two differentiated receptor populations, but this was not the case in the present and previous studies [5].

If the mutants have not altered their TbpA and TbpB expression, TbpA has an affinity for Tf six times higher than the TbpAB complex and 16 times greater than TbpB. Although this greater affinity is widely accepted, Powell et al. [12], with the same mutants, found that the TbpB molecule was more effective in binding Tf than TbpA. Perhaps this discrepancy could be caused by the different methodologies employed and the fact that these authors obtained their data from electron microscopic examination of bacteria labelled with gold-coupled Tf. In our opinion, this method is less precise than radioligand binding assays, in which total binding to the bacteria is evaluated in conditions that minimise stress to the bacterial cells. The data also suggest that the TbpAB complex is formed by single copies of $\mathrm{TbpA}$ and $\mathrm{TbpB}$, agreeing with Powell et al. [12], but in disagreement with other results that suggest that the complex would be formed by two TbpA molecules and one TbpB molecule [13], or with studies in $N$. gonorrhoeae in which a complex formed by several TbpB molecules and one molecule of TbpA is postulated [14].

The results with regard to iron uptake and growth demonstrate that both the $\mathrm{TbpA}$ and $\mathrm{TbpB}$ defective mutants are capable of incorporating iron, but only the TbpA mutant gets sufficient iron for growth. This suggests that $\mathrm{TbpB}$ could have greater importance than TbpA for iron uptake although, until now, TbpA has been assumed to be the most important. Alternatively, the binding of $\mathrm{Tf}$ to $\mathrm{TbpB}$ in the $\mathrm{TbpA}$ mutant could alter the $\mathrm{Tf}$ molecule enough to induce iron release, which would then be internalised by other non-specific mechanisms [9].

Anti-TbpB antibodies are known to be bactericidal, protective to a variable degree, and capable of inhibiting meningococcal iron uptake and growth both in vivo and in vitro [3, 11, 15]. Ala'Aldeen and Borriello [16] suggested that only anti-TbpA antibodies were bactericidal, whereas Rokbi et al. [17] found that specific anti-TbpA antibodies did not bind to live meningococcal cells. Thus, the role of antiTbpA antibodies is not clear. In the present study, specific anti-TbpA antibodies bound to the wild-type strain and to the TbpB mutant and this binding was able to block iron uptake from Tf. The blockage was much lower in the TbpB mutant, probably due to the higher affinity for $\mathrm{Tf}$ in the mutant, which could cause a displacement of the antibodies by a competition phenomenon, or to the existence of conformational epitopes unrevealed in the absence of the TbpB molecule. The results of the present study, supported by data obtained with specific anti-TbpA antibodies, that show an almost complete cross-reactivity with 28 $N$. meningitidis strains from different serogroups, serotypes and TbpB isotypes (unpublished observations), confirm that TbpA must not be discarded $a$ priori in future vaccine formulations that incorporate the iron-regulated proteins.

The authors acknowledge support from the Fondo de Investigación Sanitaria (Spanish Government, grant 96/1446) and from the local government (grant XUGA20309B95). J. A. G. holds a grant from the Fundación Areces (Spain).

\section{References}

1. Ala'Aldeen DAA, Stevenson P, Griffiths E et al. Immune responses in humans and animals to meningococcal transferrinbinding proteins: implications for vaccine design. Infect Immun 1994; 62: 2984-2990.

2. Ferrón L, Ferreirós CM, Criado MT, Pintor M. Immunogenicity and antigenic heterogeneity of a human transferrin-binding protein in Neisseria meningitidis. Infect Immun 1992; 60: 2887-2892.

3. Pintor M, Ferrón L, Gómez JA, Gorringe A, Criado MT, Ferreirós CM. Blocking of iron uptake by monoclonal antibodies specific for the Neisseria meningitidis transferrinbinding protein 2. J Med Microbiol 1996; 45: 252-257.

4. Ferrón L, Ferreirós CM, Criado MT, Andrade MP. Purification of the Neisseria meningitidis transferrin binding protein-2 (TBP2) to homogeneity using column chromatography. FEMS Microbiol Lett 1993; 109: 159-166.

5. Pintor M, Ferreirós CM, Criado MT. Characterization of the transferrin-iron uptake system in Neisseria meningitidis. FEMS Microbiol Lett 1993; 112: 159-166.

6. Cornelissen CN, Biswas GD, Tsai J, Paruchuri DK, Thompson $\mathrm{SA}$, Sparling PF. Gonococcal transferrin-binding protein 1 is required for transferrin utilization and is homologous to TonBdependent outer membrane receptors. J Bacteriol 1992; 174: $5788-5797$.

7. Anderson JE, Sparling PF, Cornelissen CN. Gonococcal transferrin-binding protein 2 facilitates but is not essential for transferrin utilization. $J$ Bacteriol 1994; 176: 3162-3170.

8. Irwin SW, Averil N, Cheng CY, Schryvers AB. Preparation and analysis of isogenic mutants in the transferrin receptor protein genes, tbpA and $t b p B$, from Neisseria meningitidis. Mol Microbiol 1993; 8: 1125-113.

9. Pintor M, Ferreirós CM, Criado MT. Energy-independent binding of iron complexed to small organic chelants by Neisseria meningitidis. J Gen Appl Microbiol 1994; 40: 23-34.

10. Pintor M, Ferreirós CM, Criado MT, Ferrón L. Expression levels of human transferrin receptors in Neisseria species. $J$ Microbiol Methods 1992; 15: 321-326.

11. Pintor M, Ferrón L, Gómez JA et al. Blocking of iron uptake from transferrin by antibodies against the transferrin binding proteins in Neisseria meningitidis. Microb Pathog 1996; 20: $127-139$

12. Powell NBL, Bishop K, Gorringe AR, Schryvers AB. Colocalization of the meningococcal binding proteins (Tbpl and $\mathrm{Tbp} 2$ ) and evaluation of their relative roles in binding human transferrin. In: Zollinger WD, Frasch CE, Deal CD (eds) Abstracts of the Tenth International Pathogenic Neisseria Conference, Baltimore. 1996: 584.

13. Boulton IC, Gorringe AR, Allison N, Gornisky B, Evans RW Characterization of the interaction between Neisseria meningitidis transferrin binding proteins and transferrin by gel filtration and surface plasmon resonance. In: WD Zollinger, CE Frasch, 
CD Deal (eds) Abstracts of the Tenth International Pathogenic Neisseria Conference, Baltimore, 1996: 562-563.

14. Cornelissen CN, Sparling PF. Binding and surface exposure characteristics of the gonococcal transferrin receptor are dependent on both transferrin-binding proteins. $J$ Bacteriol 1996; 178: $1437-1444$.

15. Danve B, Lissolo L, Mignon $\mathrm{M}$ et al. Transferrin-binding proteins isolated from Neisseria meningitidis elicit protective and bactericidal antibodies in laboratory animals. Vaccine 1993;
11: $1214-1220$.

16. Ala'Aldeen DAA, Borriello SP. The meningococcal transferrinbinding proteins 1 and 2 are both surface exposed and generate bactericidal antibodies capable of killing homologous and heterologous strains. Vaccine 1996; 14: 49-53.

17. Rokbi B, Mazarin V, Maitre-Wilmotte G, Quentin-Millet M-J. Identification of two major families of transferrin receptors among Neisseria meningitidis strains based on antigenic and genomic features. FEMS Microbiol Lett 1993; 110: 51-58. 